\title{
Real-World Glycemic Lowering Effectiveness of Linagliptin Among Adults with Type 2 Diabetes by Age, Renal Function, and Race
}

\author{
Byron J. Hoogwerf - Michele MacKenzie - Whitney Sealls • \\ Jeanine Cordova · Pranav Gandhi
}

Received: April 15, 2020 / Published online: May 27, 2020

(C) The Author(s) 2020

\section{ABSTRACT}

Introduction: To assess real-world effectiveness of linagliptin in persons with type 2 diabetes mellitus (T2DM) across a range of ages and renal function. Effectiveness was assessed in different races, with a focus on African Americans (AA).

Methods: This was a non-interventional retrospective cohort study using data in the Optum clinical database from adults with T2DM initiating linagliptin. Date of the first linagliptin prescription was the index date. Outcomes included change in glycated hemoglobin (HbA1c) and the percentage of persons achieving an $\mathrm{HbA} 1 \mathrm{c}<7 \%(53 \mathrm{mmol} / \mathrm{mol})$ during the 60-180 days following linagliptin initiation. Analyses of age by renal function were conducted. Multivariate regression analysis was

Digital Features To view digital features for this article go to https://doi.org/10.6084/m9.figshare.12292838.

Electronic supplementary material The online version of this article (https://doi.org/10.1007/s13300020-00841-X) contains supplementary material, which is available to authorized users.

B. J. Hoogwerf $(\bowtie) \cdot$ W. Sealls

Eli Lilly and Company, Indianapolis, IN, USA

e-mail: byronhoogwerf@gmail.com

M. MacKenzie · J. Cordova · P. Gandhi

Boehringer Ingelheim Pharmaceuticals, Inc.,

Ridgefield, CT, USA performed to assess change in HbA1c, controlling for an a priori list of covariates.

Results: Overall, 11,001 persons were included. Mean pre-index HbA1c value was $8.2 \%$ $(66 \mathrm{mmol} / \mathrm{mol})$, with higher levels in younger versus older persons and AAs versus other race groups. Persons initiating linagliptin had an average $\mathrm{HbA} 1 \mathrm{c}$ reduction of $0.51 \%$ $(5.6 \mathrm{mmol} / \mathrm{mol})$. Without adjusting for age, renal function, race, and pre-index $\mathrm{HbA1c}$, greater reductions in $\mathrm{HbA1c}$ were observed in younger versus older persons, persons with higher versus lower estimated glomerular filtration rate (eGFR), and AAs versus white or Asians. After multivariate analysis, variables significantly associated with a greater HbA1c reduction included higher pre-index $\mathrm{HbA1c}$ and older age.

Conclusions: These results support the HbA1clowering effectiveness of linagliptin across age, race, and renal function categories among a large real-world population of adults with T2DM.

Keywords: Effectiveness; Glycated hemoglobin; Linagliptin; Renal function; Type 2 diabetes mellitus 


\section{Key Summary Points}

Why carry out the study?

Information on efficacy of dipeptidyl peptidase-4 (DPP-4) inhibitor use is largely from clinical trials.

Few data evaluate the effects of age, renal function, and race on glycated hemoglobin (HbA1c) effectiveness.

\section{What was learned from the study?}

This real-world-evidence study shows that a single dose of linagliptin is effective across age, renal function, and race.

The findings support the use of linagliptin in older persons with type 2 diabetes who have concomitant renal compromise in a real-world setting.

\section{INTRODUCTION}

Diabetes and associated renal disease increase with age and diabetes duration, especially in African Americans (AA) [1]. Diabetes mellitus disease duration is associated with more complex treatment regimens for glycemic control and renal and cardiovascular comorbidities with concomitant polypharmacy. Several glucose-lowering agents are contraindicated in chronic kidney disease and must be discontinued, and other medications require dose adjustment [2, 3]. Use of medications that do not require dose adjustment mitigates treatment complexity.

Dipeptidyl peptidase-4 (DPP-4) inhibitors reduce glycated hemoglobin (HbA1c) in adults with type 2 diabetes mellitus (T2DM) [4-6]. Of four DPP-4 inhibitors approved for use in the US, only linagliptin requires no dose adjustment with moderate to severe renal impairment [7].

Although there are many randomized controlled clinical trial data on linagliptin [8-10], data comparing linagliptin's glycemic effectiveness in a large real-world cohort of persons with T2DM across predefined ranges of age and renal function are limited. The current study sought to determine whether linagliptin has similar glycemic effectiveness across these variables. The objective was to evaluate change in HbA1c and percentage of persons achieving an HbA1c $<7.0 \%(53 \mathrm{mmol} / \mathrm{mol})$.

\section{METHODS}

\section{Study Design}

This retrospective cohort study used data from persons in the Optum clinical electronic health records (EHR) database between July 1, 2011, and March 31, 2017 (see Fig. S1 in the electronic supplementary material). The EHR database consists of data from $>60$ million persons across the USA and Puerto Rico (see Table S1 for participant flow and Table S2 for comorbid conditions in the electronic supplementary material).

Persons were included if they had $\geq 1$ written prescription for linagliptin or single-tablet combination linagliptin/metformin between January 1, 2012, and September 30, 2016. The pre-index (for consistency with other instances) period was a period of 180 days (6 months) before the date of the first prescription for linagliptin. The post-index period was 6 months after the first linagliptin prescription. Study population included adults $\geq 40$ years old. To be considered for these analyses, they needed at least one diagnosis code for type 2 diabetes and had to have at least one HbA1c value in the 6 months before the linagliptin prescription. In addition, they had to have at least $1 \mathrm{HbA1c}$ value 60-180 days after the linagliptin prescription (the post-index period). Persons were excluded if another DPP-4 inhibitor or other glucose-lowering medication was prescribed in the pre-index period or if a new glucose-lowering medication besides linagliptin was prescribed on the index date. Persons could be on stable doses of any approved glucose-lowering medications and combinations of such 
medications in the pre-index period. Persons with malignancy or transplants were excluded.

\section{Outcome Measures}

The primary outcome variable, change in HbA1c, was calculated by subtracting a person's last pre-index HbA1c from the person's last post-index HbA1c. HbA1c goal was defined as any post-index HbA1c value of $<7 \%$ (53 $\mathrm{mmol} / \mathrm{mol}$ ).

\section{Covariates}

Demographic variables were age, age categories, sex, race, ethnicity, and US geographic region. Pre-index glucose-lowering medications were identified based on written prescription, medication administration, and medication history records in the EHR (180 days). Persons were categorized into renal function groups based on pre-index estimated glomerular filtration rate (eGFR, $\mathrm{ml} / \mathrm{min} / 1.73 \mathrm{~m}^{2}$ ) [11].

\section{Statistical Analyses}

All study variables, including pre-index and outcome measures, were analyzed descriptively. Continuous measures were compared using $t$ tests; categorical measures were compared using chi-square tests. $P$ values were not adjusted for multiple comparisons. The change in outcome measures was reported for the overall study population and in the African American cohort in predefined subgroups of persons, including age categories (40-54, 55-64, $65-74, \geq 75$ years), eGFR $(<30,30-44,45-59$, $\left.60-89, \geq 90 \mathrm{ml} / \mathrm{min} / 1.73 \mathrm{~m}^{2}\right)$, and race.

Multivariable modeling assessed the change in HbA1c in the overall sample and in the African American cohort, controlling for an a priori list of covariates. Final adjustments only included variables that affected differences in the unadjusted analyses: age, eGFR, race, and pre-index HbA1c.
Table 1 Baseline characteristics

\begin{tabular}{|c|c|}
\hline Characteristic & Value $^{\mathbf{a}}$ \\
\hline Mean age (SD), years & $64(11)$ \\
\hline \multicolumn{2}{|l|}{ Sex } \\
\hline Women & $5603(51)$ \\
\hline \multicolumn{2}{|l|}{ Race } \\
\hline African American & $1455(13.2)$ \\
\hline White & $8645(78.6)$ \\
\hline Asian & $241(2.2)$ \\
\hline Other & $660(6.0)$ \\
\hline \multicolumn{2}{|l|}{ Ethnicity } \\
\hline Hispanic & $927(8.4)$ \\
\hline Non-Hispanic & $9550(86.8)$ \\
\hline Unknown & $524(4.8)$ \\
\hline $\begin{array}{l}\text { Baseline HbAlc, mmol/mol; mean }(\mathrm{SD}) / \\
\text { \%; mean }(\mathrm{SD})\end{array}$ & $\begin{array}{l}66(18) / 8.2 \\
(1.6)\end{array}$ \\
\hline $\begin{array}{l}\text { Baseline eGFR, } \mathrm{ml} / \mathrm{min} / 1.73 \mathrm{~m}^{2} \text {; mean } \\
\quad(\mathrm{SD})\end{array}$ & $68.7(26.8)$ \\
\hline \multicolumn{2}{|l|}{ Baseline glucose-lowering therapy ${ }^{\mathrm{b}}$} \\
\hline Metformin monotherapy & $1993(18.1)$ \\
\hline Sulfonylurea monotherapy & $1022(9.3)$ \\
\hline Any use of metformin & $5454(49.6)$ \\
\hline Any use of sulfonylureas & $3882(35.3)$ \\
\hline Any use of insulin & $2816(25.6)$ \\
\hline Other medications & $2559(23.3)$ \\
\hline No glucose-lowering medications & $2440(22.2)$ \\
\hline
\end{tabular}

$e G F R$ estimated glomerular filtration rate, $H b A l c$ glycated hemoglobin, $S D$ standard deviation

a Values are $n(\%)$ unless otherwise indicated

b Used in $>3 \%$ of persons

Baseline $=$ pre-index value

\section{RESULTS}

\section{Study Population}

Overall, 11,001 persons with T2DM met all inclusion and exclusion criteria and had both 


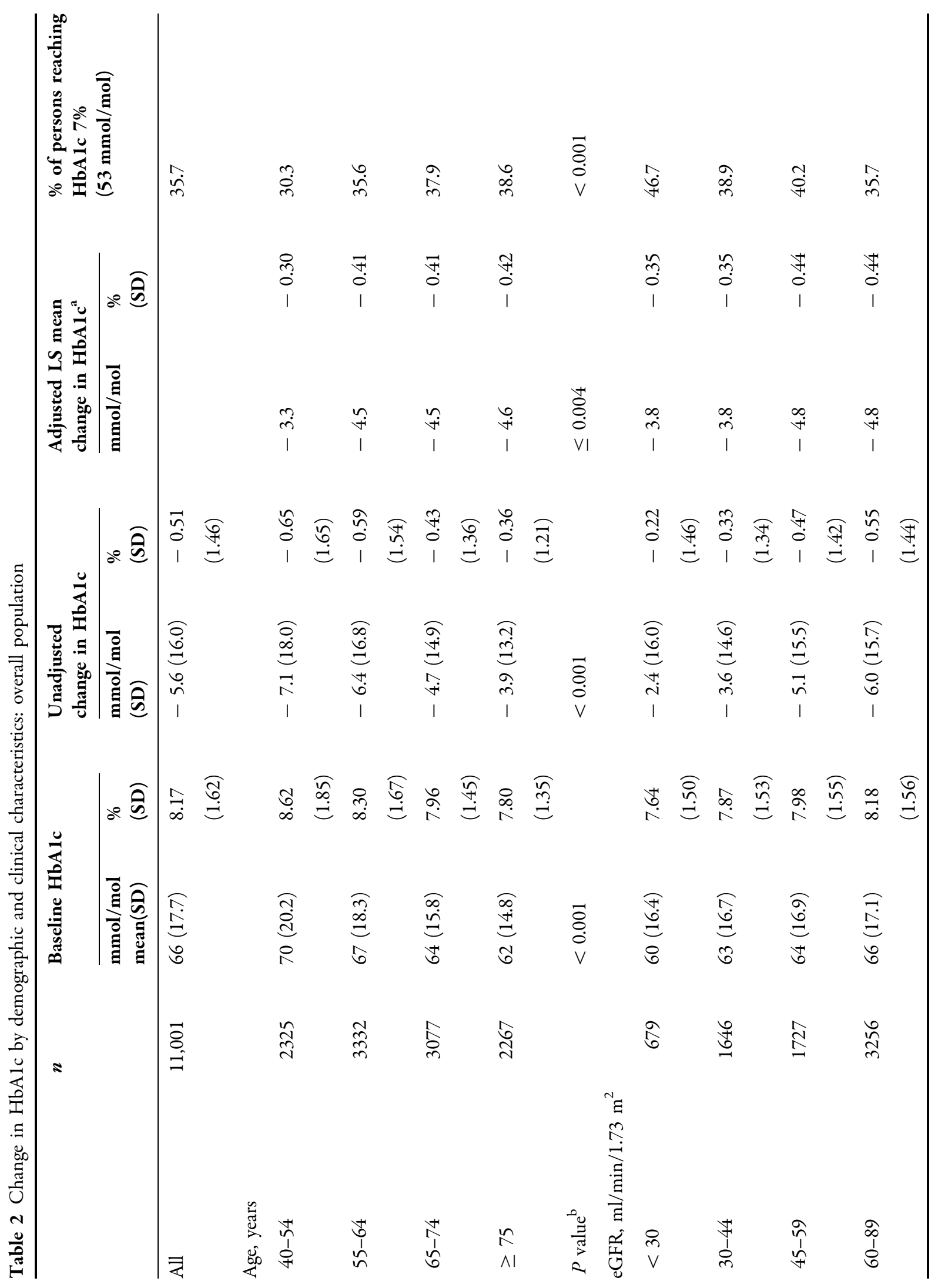




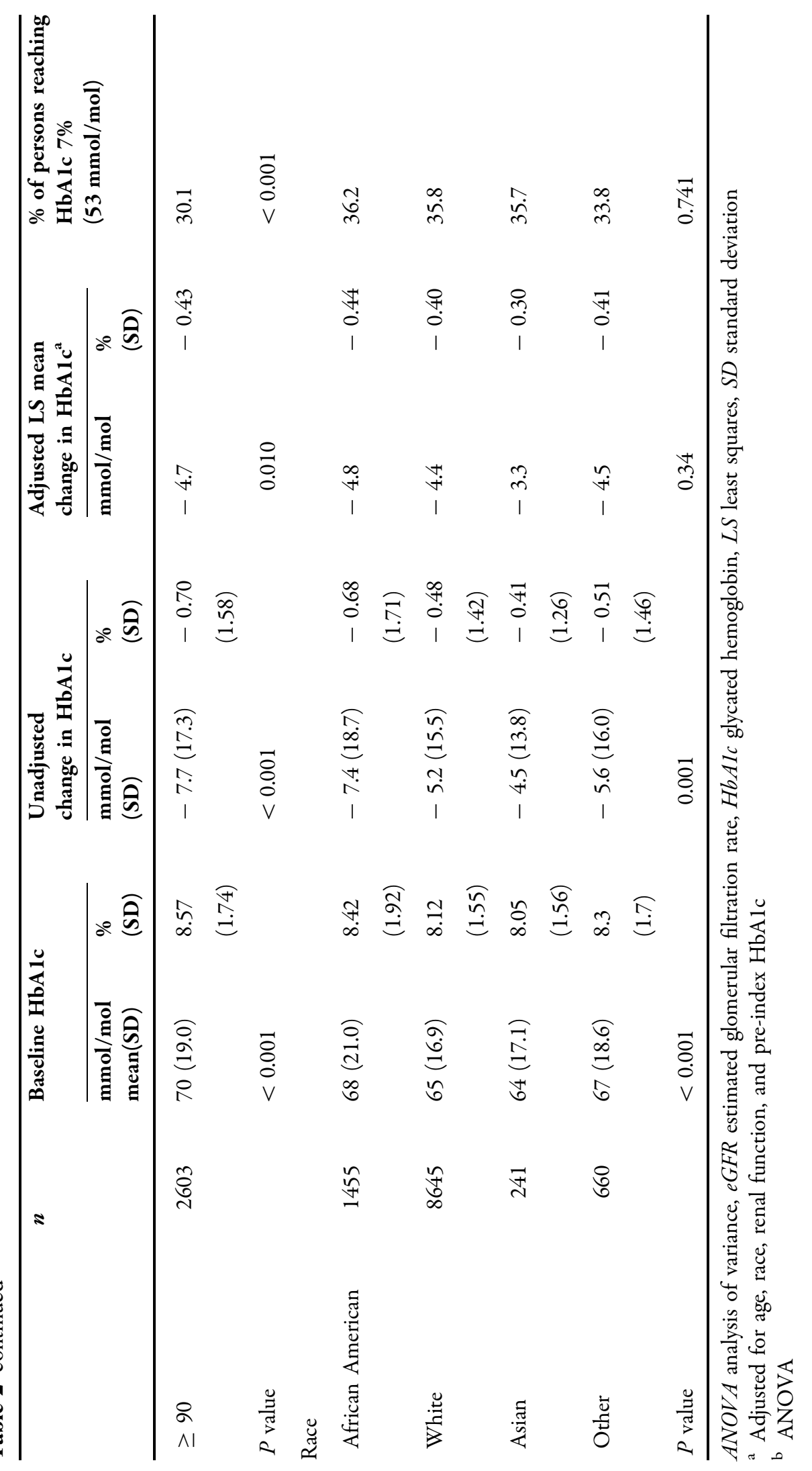




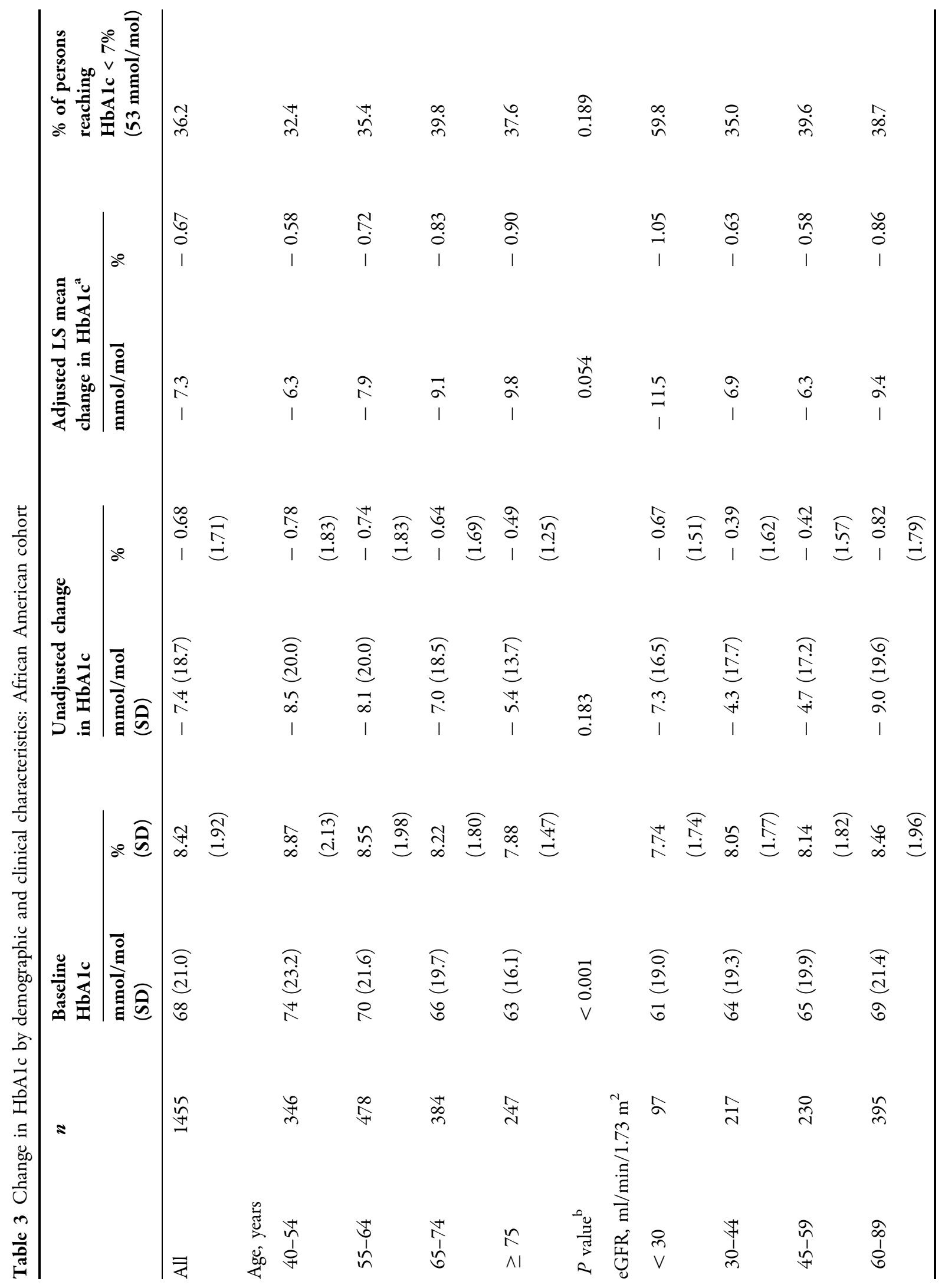




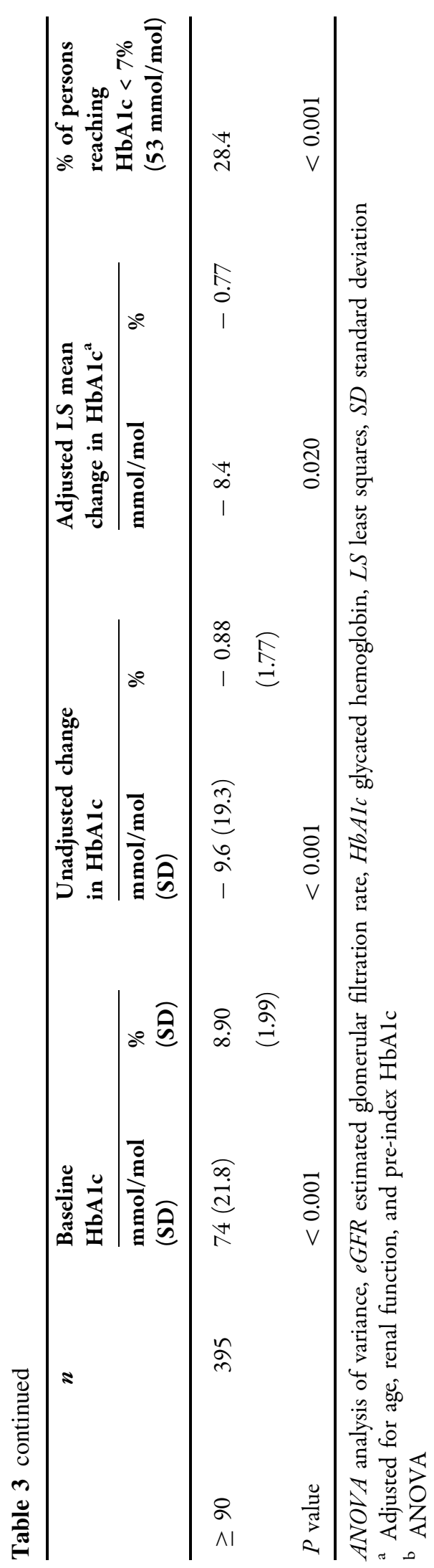

pre-index (baseline) and post-index HbA1c values available. Characteristics of the study cohort are shown in Table 1 and Table S2 in the electronic supplementary material. Background glucose-lowering medication use is summarized in Table 1 . About $22 \%$ were on no other medications, about $50 \%$ on metformin alone or in combination, and about $25 \%$ on insulin alone or in combination. There were smaller numbers of persons on various combinations of background medications including three medications $(n=1153,10 \%)$ or four or more medications $(n=330,3.0 \%)$.

\section{Adjusted and Unadjusted HbA1c Changes: Persons Reaching HbA1c Goal}

In the overall population, the unadjusted analysis demonstrated a greater change in HbA1c in younger versus older persons $(P<0.001)$ and those with higher versus lower eGFR $(P<0.001)$ (Table 2). Pre-index HbA1c was higher in younger versus older persons and those with higher versus lower eGFR. African Americans had a greater change in HbA1c versus whites or Asians $(P<0.001)$. In the African American cohort, the unadjusted analyses also demonstrated a greater change in HbA1c in younger versus older persons $(P<0.001)$ and those with higher versus lower eGFR $(P<0.001)$ (Table 3).

The adjusted analyses diminished some of the differences in the unadjusted analyses $(P$ values reported). Overall, $36 \%$ of all persons achieved an HbA1c goal of $<7 \%$ $(53 \mathrm{mmol} / \mathrm{mol})$ in the post-index period. The proportion of persons reaching this goal was different across age categories, with fewer younger than older persons reaching goal, and across renal function categories, with fewer persons with higher eGFR reaching goal. The proportion of persons reaching goal was not significantly different across race categories. In the African American cohort, decreases in HbA1c were observed across all age and renal function categories, but small sample size limited statistical comparisons. Changes in HbA1c cross-tabulated by age and renal function are 
shown in Table S3 in the electronic supplementary material.

\section{DISCUSSION}

This study demonstrates the glycemic effectiveness of linagliptin in adults with T2DM across a range of ages, renal function, and race in a real-world practice setting. These observations expand on previous clinical trial results in smaller groups of persons with renal impairment $[6,8,12,13]$, older age $[8,9,14]$, and African American race $[10,15]$. HbA1c reductions were different across age and renal function. Such differences are common in real-world studies. Change in HbA1c is often a function of baseline HbA1c (greater reduction with high baseline values). Because of pre-index HbA1c differences across groups, it was important to adjust for this variable. Unadjusted differences across age and renal function categories were attenuated in the adjusted analyses. Importantly, resultant reductions in HbA1c were roughly comparable across all age and renal function categories for the whole group and the African American cohort.

These data add to the observations from other trials of the glycemic efficacy of linagliptin in a broad range of populations characterized by age, declining renal function, and African American race. In addition, linagliptin use in large randomized trials does not increase the risk for renal or cardiovascular disease [16-18]. The main limitation of this study is whether the results are generalizable, especially in some cohorts that are not fully represented.

\section{CONCLUSIONS}

The findings in the current study support the use of linagliptin in older persons with T2DM who have concomitant renal compromise in a real-world setting.

\section{ACKNOWLEDGEMENTS}

Funding. This study and the journals rapid service fee were funded by Boehringer Ingelheim.

Authorship. The authors meet criteria for authorship as recommended by the International Committee of Medical Journal Editors (ICMJE), were fully responsible for all content and editorial decisions, were involved at all stages of manuscript development, and have approved the final version of the manuscript that reflects the authors' interpretation and conclusions. The authors received no direct compensation related to the development of the manuscript.

Medical Writing and Editorial Support. Writing support was provided by Linda Merkel, PhD, and Marissa Buttaro, MPH, of Elevate Scientific Solutions, which was contracted and compensated by Boehringer Ingelheim Pharmaceuticals, Inc., for these services.

Disclosures. Byron J. Hoogwerf is a minor stockholder of Eli Lilly and Company, current affiliation Sarasota, FL, USA. Michele MacKenzie is a previous employee of Boehringer Ingelheim Pharmaceuticals, Inc. currently employed by Regeneron Pharmaceuticals, Tarrytown, NY, USA. Whitney Sealls is an employee and stockholder of Eli Lilly and Company. Jeanine Cordova is an employee of Boehringer Ingelheim Pharmaceuticals, Inc. Pranav Gandhi is a previous employee of Boehringer Ingelheim Pharmaceuticals, Inc., currently employed by Allergan.

Compliance with Ethics Guidelines. We thank Optum ${ }^{\mathrm{TM}}$ (Eden Prairie, MN) for data acquisition, access, and analysis. The data were all de-identified and fully comply with Health Insurance Portability and Accountability Act (HIPAA) regulations.

Data Availability. The datasets during and/ or analyzed during the current study are available from the corresponding author on reasonable request. 
Open Access. This article is licensed under a Creative Commons Attribution-NonCommercial 4.0 International License, which permits any non-commercial use, sharing, adaptation, distribution and reproduction in any medium or format, as long as you give appropriate credit to the original author(s) and the source, provide a link to the Creative Commons licence, and indicate if changes were made. The images or other third party material in this article are included in the article's Creative Commons licence, unless indicated otherwise in a credit line to the material. If material is not included in the article's Creative Commons licence and your intended use is not permitted by statutory regulation or exceeds the permitted use, you will need to obtain permission directly from the copyright holder. To view a copy of this licence, visit http://creativecommons.org/licenses/by$\mathrm{nc} / 4.0 /$.

\section{REFERENCES}

1. Warren B, Rebholz CM, Sang Y, et al. Diabetes and trajectories of estimated glomerular filtration rate: a prospective cohort analysis of the atherosclerosis risk in communities study. Diabetes Care. 2018;41: 1646-53.

2. American Diabetes Association. 9. Pharmacologic approaches to glycemic treatment: standards of medical care in diabetes-2019. Diabetes Care. 2019;42:S90-S102.

3. Garber AJ, Abrahamson MJ, Barzilay JI, et al. Consensus statement by the American Association of Clinical Endocrinologists and American College of Endocrinology on the comprehensive type 2 diabetes management algorithm-2018 executive summary. Endocr Pract. 2018;24:91-120.

4. Davis TM. Dipeptidyl peptidase-4 inhibitors: pharmacokinetics, efficacy, tolerability and safety in renal impairment. Diabetes Obes Metab. 2014;16: 891-9.

5. Esposito K, Cozzolino D, Bellastella G, et al. Dipeptidyl peptidase-4 inhibitors and HbA1c target of $<7 \%$ in type 2 diabetes: meta-analysis of randomized controlled trials. Diabetes Obes Metab. 2011;13:594-603.

6. Thomas MC, Paldanius PM, Ayyagari R, Ong SH, Groop PH. Systematic literature review of DPP-4 inhibitors in patients with type 2 diabetes mellitus and renal impairment. Diabetes Ther. 2016;7: 439-54.

7. Patorno E, Gopalakrishnan C, Bartels DB, Brodovicz KG, Liu J, Schneeweiss S. Preferential prescribing and utilization trends of diabetes medications among patients with renal impairment: emerging role of linagliptin and other dipeptidyl peptidase 4 inhibitors. Endocrinol Diabetes Metab. 2018;1: e00005.

8. Ning G, Bandgar T, Hehnke U, Lee J, Chan JCN. Efficacy and safety of linagliptin in 2681 Asian patients stratified by age, obesity, and renal function: a pooled analysis of randomized clinical trials. Adv Ther. 2017;34:2150-62.

9. Schernthaner G, Barnett AH, Patel S, Hehnke U, von Eynatten M, Woerle HJ. Safety and efficacy of the dipeptidyl peptidase- 4 inhibitor linagliptin in elderly patients with type 2 diabetes: a comprehensive analysis of data from 1331 individuals aged $\geq 65$ years. Diabetes Obes Metab. 2014;16:1078-86.

10. Thrasher J, Kountz DS, Crowe S, Woerle HJ, von Eynatten M. Efficacy and safety of the dipeptidyl peptidase-4 inhibitor linagliptin in black/African American patients with type 2 diabetes: pooled analysis from eight Phase III trials. Postgrad Med. 2015;127:419-28.

11. Levey AS, Stevens LA, Schmid $\mathrm{CH}$, et al. A new equation to estimate glomerular filtration rate. Ann Intern Med. 2009;150:604-12.

12. Groop PH, Del Prato S, Taskinen MR, et al. Linagliptin treatment in subjects with type 2 diabetes with and without mild-to-moderate renal impairment. Diabetes Obes Metab. 2014;16:560-8.

13. McGill JB, Sloan L, Newman J, et al. Long-term efficacy and safety of linagliptin in patients with type 2 diabetes and severe renal impairment: a 1-year, randomized, double-blind, placebo-controlled study. Diabetes Care. 2013;36:237-44.

14. Barnett AH, Huisman H, Jones R, von Eynatten M, Patel S, Woerle HJ. Linagliptin for patients aged 70 years or older with type 2 diabetes inadequately controlled with common antidiabetes treatments: a randomised, double-blind, placebo-controlled trial. Lancet. 2013;382:1413-23.

15. Thrasher J, Daniels K, Patel S, Whetteckey J, Woerle HJ. Efficacy and safety of linagliptin in black/African American patients with type 2 diabetes: a 6-month, randomized, double-blind, placebo-controlled study. Endocr Pract. 2014;20:412-20.

16. Rosenstock J, Kahn SE, Johansen OE, et al. Effect of linagliptin vs glimepiride on major adverse 
cardiovascular outcomes in patients with type 2 diabetes: the CAROLINA randomized clinical trial. JAMA. 2019;322:1155-1166.

17. Rosenstock J, Perkovic V, Johansen OE, et al. Effect of linagliptin vs placebo on major cardiovascular events in adults with type 2 diabetes and high cardiovascular and renal risk: the CARMELINA randomized clinical trial. JAMA. 2019;321:69-79.

18. Groop PH, Cooper ME, Perkovic V, et al. Linagliptin and its effects on hyperglycaemia and albuminuria in patients with type 2 diabetes and renal dysfunction: the randomized MARLINA-T2D trial. Diabetes Obes Metab. 2017;19:1610-9. 